\title{
Influência da alumina sintetizada por reação de combustão nas propriedades de compósitos com matriz de polipropileno
}

\author{
Influence of the alumina synthesized by combustion \\ reaction on the properties of composites \\ with polypropylene matrix
}

\author{
Amanda Maciel Alves ${ }^{1}$, Aylanna Priscila Marques de Araújo ${ }^{1}$, Pankaj Agrawal ${ }^{1}$, \\ Shirley Nóbrega Cavalcanti ${ }^{1}$, Rafaela Reis Arimatéia ${ }^{1}$, Normanda Lino de Freitas ${ }^{1}$,
}

Tomás Jeferson Alves de Mélo 1

\footnotetext{
${ }^{1}$ Programa de Pós-Graduação em Ciência e Engenharia de Materiais, PPG-CEMat/UFCG, Rua: Aprígio Veloso, 882, CP: 58429-140, Campina Grande, Paraíba, Brasil.

e-mail: amanda.polanski@gmail.com; tomas.jeferson@ufcg.edu.br
}

\section{RESUMO}

O polipropileno (PP) é um dos polímeros mais utilizados em produtos manufaturados em plásticos, por isso, estudos em compósitos têm sido realizados na tentativa de modificar suas propriedades e ampliar ainda mais seu uso. Portanto, este trabalho teve como objetivo utilizar alumina sintetizada por reação de combustão em laboratório e avaliar sua influência em concentrações de 1,3 e 5 pcr (partes por cem de resina), nas propriedades de compósitos com matriz de PP. A alumina sintetizada foi misturada ao PP numa extrusora de rosca dupla e, posteriormente, corpos de prova foram moldados por injeção e caracterizados por Difração de Raios X (DRX), Calorimetria Exploratória Diferencial (DSC), Microscoscopia Eletrônica de Varredura (MEV), propriedades mecânicas (tração e impacto), inflamabilidade e análise reológica em regime oscilatório. Os resultados de DRX mostraram que a alumina sintetizada, possui estrutura cristalina do tipo coríndon e quando misturada ao PP não alterou sua estrutura cristalina do PP, entretando dificultou a cristalização, resultado confirmado também por DSC pela redução do grau de cristalinidade. As transições térmicas (Tm e Tc) do PP praticamente não foram alteradas nos compósitos. Na avaliação das propriedades mecânicas, o módulo aumentou e resistência à tração e impacto diminuíram, o que foi atribuído a formação de aglomerados observados no MEV. No teste de inflamabilidade, a alumina retardou o processo de queima dos compósitos e contribuiu para redução da emissão de fumaça e gotejamento quando comparado com o PP. Na análise reológica o PP e os compósitos apresentaram comportamento pseudoplástico e, nos compósitos, o aumento da concentração de alumina promoveu redução na viscosidade. Já o módulo de armazenamento dos compósitos, aumentou com a concentração de alumina corroborando com os resultados das propriedades mecânicas.

Palavras-chave: Polipropileno, alumina, compósitos.

\section{ABSTRACT}

Polypropylene (PP) is one of the most used polymers in manufactured products in plastics, therefore, studies on composites have been carried out in an attempt to modify its properties and further extend its use. The aim of this work was to use alumina synthesized by combustion reaction in the laboratory and to evaluate its influence in concentrations of 1, 3 and 5 parts per hundred of resin (phr) in the properties of composites with PP matrix. PP/alumina composites where prepared by extrusion followed by injection molding and characterized by X-Ray Diffraction (XRD), Differential Scanning Calorimetry (DSC) Scanning Electron Microscopy (SEM), mechanical properties (tensile and impact strength tests), flammability and rheological behavior under oscillatory shear flow. XRD results showed that the synthesized alumina has a crystalline structure of the corundum type and when mixed with PP was not affected crystalline structure of PP, however, the addition of alumina to PP led to a decrease in its crystallinity, a result also confirmed by DSC. The thermal transitions ( Tm and $\mathrm{Tc}$ ) of PP were practically unchanged in the composites. In the evaluation of the mechanical proper- 
ties, the modulus increased and tensile strength and impact decreased, which was attributed to the formation of agglomerates observed in SEM. In the flammability test, the alumina delayed the burning process of the composites and contributed to reduce the emission of smoke and dripping when compared to neat PP. In the rheological analysis the PP and the composites presented a shear thinning behavior and, in the composites, the increase of the alumina concentration promoted reduction in the viscosity. The storage modulus of the composites increased with the alumina concentration, corroborating the results of the mechanical properties.

Keywords: Polypropylene, alumina, composites.

\section{INTRODUÇÃO}

Os compósitos poliméricos utilizando diferentes tipos de cargas são sempre uma alternativa no desenvolvimento de novos materiais, principalmente devido à possibilidade de modificação nas propriedades do polímero e ampliação do seu uso [1]. Nesse contexto, o polipropileno (PP) é um dos polímeros comerciais mais utilizados do mercado em produtos manufaturados em plásticos e tem despertado interesse de pesquisadores no estudo de misturas de PP com diversas cargas inorgânicas [2-6]. A obtenção de compósitos com matriz de PP tem sido uma forma de aumentar a sua utilização, considerando que o mesmo atinge cerca de $20 \%$ da produção mundial de poliolefinas e que seu potencial de reciclagem e baixo custo tornam-o mais atraente comercialmente. Portanto, à procura de novas aplicações é o que tem motivado o interesse em melhorar suas propriedades por meio da mistura com cargas, formando os compósitos e nanocompósitos [7,8]. A alumina $\left(\mathrm{Al}_{2} \mathrm{O}_{3}\right)$ tem sido utilizada por pesquisadores em diferentes aplicações, devido às suas excelentes propriedades dielétricas, boa condutividade térmica, alta rigidez mecânica e resistência a ácidos e bases fortes, mesmo em temperaturas elevadas, porém, o seu uso como cargas em polímeros ainda é incipiente [9]. A maioria dos estudos com alumina utiliza polímeros de custo mais elevado, tais como poli (tereftalato de etileno), poliamidas, resinas de poliuretano e epóxi $[9,10]$. Entretanto, algumas pesquisas com alumina foram desenvolvidas na obtenção de nanocompósitos com matrizes poliméricas de custo mais baixo, principalmente o PP, pela possibilidade de melhorar as propriedades mecânicas e térmicas, reduzir a inflamabilidade e diminuir o ciclo de moldagem do polímero por alterar sua cinética de cristalização [11].

Como exemplos de pesquisas com PP e alumina, RAO et al. [4] desenvolveram nanocompósitos por meio da técnica de mistura por fusão de PP/alumina e PP/argila variando as composições de alumina e argila. Utilizaram dois modificadores poliméricos e um agente de acoplamento para melhorar a dispersão das cargas utilizadas. Através da técnica de DRX identificaram a formação de nanocompósitos intercalados e esfoliados. A presença do modificador polimérico e do agente de acoplamento foi eficaz quanto à dispersão das cargas e houve uma melhoria de $20-25 \%$ nas propriedades mecânicas e térmicas. ZHAO e LI [12], modificaram as superfícies das nanopartículas de alumina com o agente de acoplamento silano, em seguida foram misturadas com o PP nas concentrações de 1,5 à 5\% de alumina em uma extrusora rosca dupla e moldados por injeção. Observaram que a alumina modificada por silano, na forma de nanopartículas influenciou significativamente na redução do tamanho médio do esferulito e na temperatura de cristalização do PP durante o processo de resfriamento, sugerindo que as nanopartículas atuaram como agentes nucleantes podendo contribuir na redução do ciclo de produção. Houve também um aumento no módulo e resistência à tração proporcional ao aumento da concentração de alumina no qual foi atribuído a boa interação entre a matriz e a carga, devido ao agente silano. DUAN e FU [13] utilizaram o poli (n - acrilato de octadecil) - PnOA sintetizado em laboratório, nas concentrações de 3 e $5 \%$ em peso como agente de compatibilização para melhorar a adesão interfacial do compósito polipropileno/alumina trihidratada (PP/ATH). O PnOA foi misturado previamente à ATH num misturador, em seguida, adicionou-se PP. Estas misturas foram então diluídas numa extrusora dupla rosca. As razões de massa de ATH para PP foram variadas de 0/100, 40/100 a 60/100. Em seguida, as misturas obtidas foram moldadas por injeção para realização dos ensaios de tração e impacto. Os resultados mostraram que o poli ( $\mathrm{n}$ - acrilato de octadecil) melhorou significativamente as propriedades mecânicas e o comportamento reológico dos compósitos de PP/ATH. As imagens obtidas no MEV corroboraram com os resultados das propriedades mecânicas que mostraram boa adesão interfacial entre o PP e a ATH. O poli (n - acrilato de octadecil) foi indicado pelos autores como um agente de compatibilização bastante promissor em compósitos de poliolefinas e alumina trihidratada. LI et al.[14] avaliaram a influência de dois métodos de obtenção de compósitos de $\mathrm{PP} / \mathrm{Al}_{2} \mathrm{O}_{3}$, moagem mecânica (MG) e mistura por fusão (MM). Na moagem mecânica, uma configuração automática de $\mathrm{MG}$ foi aplicada para misturar a seco $\mathrm{PP}$ e $\mathrm{Al}_{2} \mathrm{O}_{3}$ por $2 \mathrm{~h}$ para formar uma estrutura tipo núcleo-casca. Após esta fase mecânica de mistura a seco, a mistura foi prensada a quente. Os compósitos de $\mathrm{PP} / \mathrm{Al}_{2} \mathrm{O}_{3}$ obtidos por $\mathrm{MM}$ foram reparados utilizando um misturador interno à $200{ }^{\circ} \mathrm{C}$. Posteriormente, a mistura foi cortada em pedaços e prensada a quente. A técnica de MG, produziu compósitos com uma estrutura segregada como pôde ser visto no MEV. Essa estrutura afetou a estabilidade térmica e recristalização do compósito, melhorando a dissipação de calor. Houve um aumento no módulo e redução na 
tração proporcional ao aumento do teor de alumina, independentemente do método utilizado.

Na maioria dos trabalhos encontrados na literatura, os estudos sobre desenvolvimento de compósitos e nanocompósitos de PP/alumina, utilizaram a alumina comercial para ser adicionada ao PP, esse trabalho diferentemente irá utilizar uma alumina sintetizada no laboratório por reação de combustão, que é um método que tem se apresentado mais eficaz na produção de pós com tamanho de partículas nanométricas, elevada área superficial e alto grau de pureza. É considerado um método fácil, seguro, rápido, de baixo consumo de energia e que possibilita a reprodução de pós-cerâmicos em escala semi-piloto [15-19]. Portanto, nesse contexto, o presente trabalho tem como objetivo investigar a influência de alumina sintetizada por reação de combustão em laboratório nas concentrações de 1, 3 e 5 pcr, nas propriedades de compósitos com matriz de polipropileno (PP).

\section{MATERIAIS E MÉTODOS}

\subsection{MATERIAIS}

O Polipropileno (PP) utilizado neste trabalho foi o H103, fornecido gentilmente pela Braskem S.A, com índice de fluidez (IF) de 40g/10min $\left(230^{\circ} \mathrm{C} / 2,16 \mathrm{~kg}\right.$ - ASTM D 1238). Alumina (Al) sintetizada pelo método de reação por combustão de acordo com os procedimentos utilizados por SILVA et al. [17] e COSTA e KIMINAMI [18].

\subsection{MÉTODOS}

\subsubsection{Preparação dos compósitos de polipropileno/alumina}

Os compósitos de polipropileno (PP) e alumina (Al) foram preparados em duas etapas: na primeira etapa obteve-se um concentrado na proporção de 1:4 de PP e alumina em um misturador interno RHEOMIX 600 da Thermo Scientific. Na segunda etapa o concentrado foi moído em moinho de facas e diluído no PP nas concentrações de 1, 3 e 5 pcr de alumina, em uma extrusora de rosca dupla corrotacional modular, modelo ZSK de $18 \mathrm{~mm}$ da Coperion-Werner-Pfleiderer, com velocidade de rosca de $200 \mathrm{rpm}$ e uma taxa de alimentação de $5 \mathrm{~kg} / \mathrm{h}$. A temperatura nas zonas do cilindro da extrusora, cabeçote e matriz foi de $200^{\circ} \mathrm{C}$. Na configuração de rosca projetada para a obtenção dos compósitos, foram utilizadas quatro seções de misturas com elementos dispersivos (malaxadores) e distributivos (tipo turbina), conforme Figura 1. Após a mistura na extrusora, os grânulos foram secos, numa estufa à vácuo com temperatura de $80^{\circ} \mathrm{C}$ durante 4 horas.

Em seguida, os grânulos extrudados e secos foram utilizados para obtenção de corpos de prova em uma Injetora Arburg, Modelo Allrounder 270C Golden Edition. A temperatura de moldagem foi de $200^{\circ} \mathrm{C}$ e a temperatura do molde foi de $20^{\circ} \mathrm{C}$. Os corpos de prova injetados foram utilizados para ensaios de tração ASTM D638 - 14 [19], impacto - ASTM D256 - 10 [20] e demais caracterizações realizadas no trabalho.

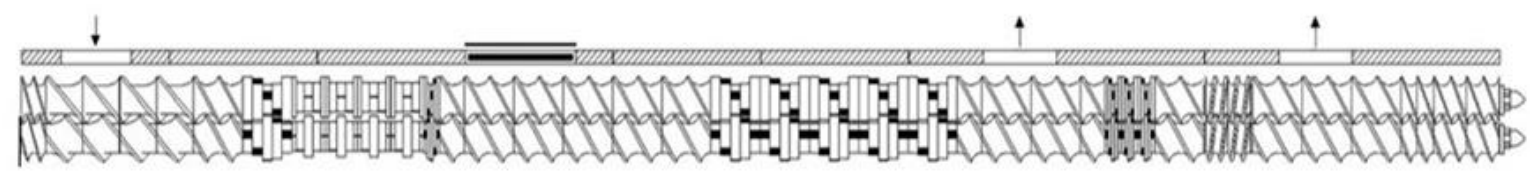

Figura 1: Perfil de rosca utilizado na extrusora de rosca dupla corrotacional [21].

\subsubsection{Técnicas de caracterização}

\subsubsection{Difração de Raios X (DRX)}

As análises de DRX da alumina sintetizada por reação de combustão e dos compósitos PP/alumina, foram realizadas no aparelho XRD-6000 Shimadzu, utilizando-se radiação K $\alpha$ do cobre, tensão de $40 \mathrm{KV}$, corrente de $30 \mathrm{~mA}$, varredura entre $2 \theta$ de $2^{\circ}$ a $80^{\circ}$ e velocidade de varredura de $2^{\circ} / \mathrm{min}$. A análise dos compósitos foi realizada em corpos de prova moldados por injeção. 


\subsubsection{Calorimetria Exploratória Diferencial (DSC)}

Os ensaios de DSC dos compósitos PP/alumina foram feitos em amostras retiradas de corpos de prova moldados por injeção, utilizando um calorímetro da marca TA Instruments, modelo Q20. A faixa de temperatura utilizada foi de 25 a $250^{\circ} \mathrm{C}$, a uma taxa de aquecimento/resfriamento de $10^{\circ} \mathrm{C} / \mathrm{min}$ sob atmosfera de nitrogênio.

\subsubsection{Teste de Inflamabilidade Horizontal (UL 94 HB)}

Esse teste foi realizado em corpos de prova injetados dos compósitos PP/alumina, de acordo com a normalização da Underwrites Laboratories, (Norma UL 94) [22]. A taxa de queima linear "V", em milímetros por minuto, para cada corpo de prova foi calculado, usando-se a Equação 1:

$$
V=60 \frac{L}{t}
$$

Onde:

$\mathrm{V}=$ taxa de queima linear em $\mathrm{mm} /$ minuto

$\mathrm{L}=$ comprimento danificado no corpo de prova, em milímetros.

$\mathrm{t}=$ tempo em segundos.

\subsubsection{Análise morfológica}

Para a análise morfológica, as superfícies de fratura das amostras dos compósitos PP/alumina submetidas a ensaios de resistência de impacto foram revestidas com ouro e analisadas utilizando um microscópio electrônico de varredura Shimadzu SS X550 Super Scan com EDX. A tensão utilizada no filamento variou entre 10 e $15 \mathrm{kV}$.

\subsubsection{Propriedades Mecânicas}

Os ensaios de tração foram realizados numa máquina universal de ensaios Shimadzu AG-IS $100 \mathrm{kN}$, de acordo com a norma ASTM - D638 - 14, em amostras do tipo I, operando a uma velocidade de 50 mm / minuto. Os ensaios de resistência ao impacto Izod foram realizados de acordo com ASTM - D256 - 10 em amostras entalhadas, com dimensões de 63,5 mm x 12,7 mm x 3,2 mm, à temperatura ambiente utilizando um aparelho Ceast Resil 5.5. Os resultados relatados são a média de dez amostras dos compósitos PP/alumina.

\subsubsection{Propriedades reológicas em regime dinâmico-oscilatório.}

Os ensaios reológicos em regime oscilatório foram realizados em reômetro Anton Paar Physica MCR 301, equipado com geometria de placas paralelas de $25 \mathrm{~mm}$ de diâmetro, em temperatura de $200{ }^{\circ} \mathrm{C}$, gap entre as placas de $1 \mathrm{~mm}$, e frequência angular variando de 0,1 a $600 \mathrm{rad} / \mathrm{s}$, sob atmosfera de ar. A deformação, dentro da região de viscoelasticidade linear, utilizada foi de $1 \%$. Estas análises foram realizadas nos compósitos PP/alumina extrudados.

\section{RESULTADOS E DISCUSSÃO}

\subsection{Caracterização da alumina e dos compósitos polipropileno/alumina}

\subsubsection{Difração de Raios X (DRX)}

Na Figura 2, está apresentado o difratograma da alumina sintetizada por reação de combustão em laboratório. Observa-se no difratograma a presença da fase cristalina majoritária $\alpha-\mathrm{Al}_{2} \mathrm{O}_{3}$, sob a forma do mineral Coríndon, a forma mais comum de alumina cristalina, sem a presença de fases secundárias. Pode-se observar que todos os picos têm elevada intensidade, indicando que a amostra sintetizada por reação de combustão apresenta elevada cristalinidade, o mesmo padrão foi observado por FREITAS et al. [23], CASTRO et al. [24], SILVA et al. [25], SHARMA et al. [26], FERET et al. [27] e RAMALHO, et al. [28] utilizando a mesma rota de síntese. 


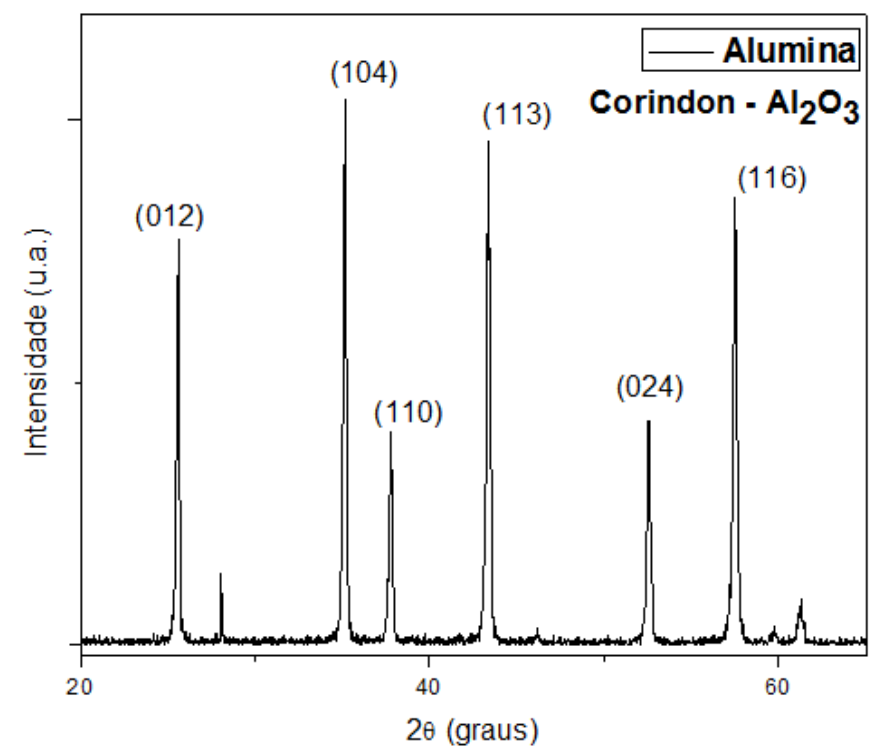

Figura 2: Difratograma de raio $X$ da alumina sintetizada por reação de combustão.

Na Figura 3, estão ilustrados os difratogramas do PP e dos compósitos de PP com 1, 3 e 5 pcr de alumina sintetizada. Observa-se que os compósitos apresentam os mesmos picos de difração referentes à fase $\alpha$ cristalina do $\mathrm{PP}$, na faixa de $2 \theta \sim 10^{\circ}$ a $30^{\circ}$, indicando que a alumina não alterou a estrutura cristalina do polímero nas concentrações utilizadas, conforme observado também em outro trabalho [11,14]. Contudo, verifica-se uma redução na intensidade de todas as reflexões dos compósitos em relação ao PP (exemplo em destaque no pico principal à esquerda da Figura 3), provavelmente as partículas da alumina dificultam a cristalização do PP, conforme também foi observado por LIBANO et al. [29]. Nos compósitos, ainda é possível identificar a presença dos picos de difração característicos da alumina, cujas intensidades, aumentam proporcionalmente ao aumento do teor da alumina (indicado por seta no destaque à direita da Figura 3).

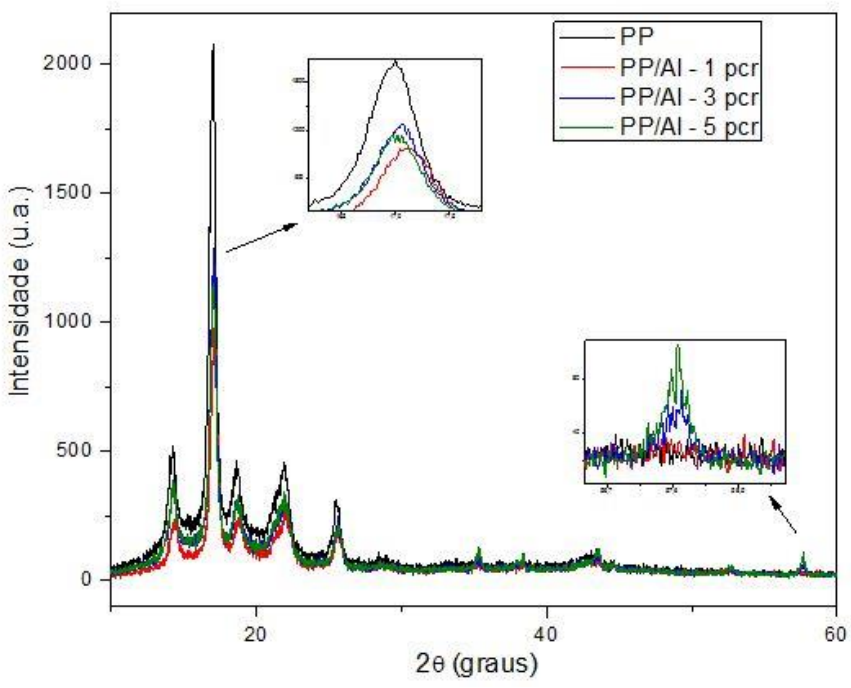

Figura 3: Difratogramas de raios X do PP e dos compósitos de PP/alumina.

\subsubsection{Calorimetria Exploratória Diferencial (DSC)}

As análises de DSC foram realizadas durante o primeiro ciclo de aquecimento e resfriamento do PP e dos compósitos de PP com 1, 3 e 5 pcr de alumina. Os resultados estão apresentados nas Figuras 4 (a) e (b) e na Tabela 1. Nas curvas termogravimétricas da Figura 4 (a), a temperatura de fusão cristalina (Tm) encontrada do PP é de $165,9^{\circ} \mathrm{C}$, próxima dos valores determinados na literatura que estão em torno de $165^{\circ} \mathrm{C}$ [30]. Para 
os compósitos, a Tm aumentou para $166,2{ }^{\circ} \mathrm{C}$ apenas na presença de 5 pcr de alumina. Em geral as cargas restringem a mobilidade molecular e este efeito é mais pronunciado em concentrações mais elevadas, influenciando diretamente nas transições térmicas dos polímeros. As curvas termogravimétricas de cristalização apresentados na Figura 4 (b) indicam que a temperatura de cristalização (Tc) também foi pouco afetada pela presença da alumina, onde indica que as partículas de alumina não afetam consideravelmente na cinética de cristalização do PP, provavelmente por não apresentar atividade superficial para atuar como agente nucleante e possuir tamanho médio de partículas elevado [9,12,28]. Já o grau de cristalinidade (Gc) do PP nos compósitos, diminuiu proporcional ao aumento do teor de alumina, conforme os valores calculados pela entalpia de fusão dividida pela entalpia de fusão do PP considerando $100 \%$ cristalino, apresentados na Tabela 1 . Estes resultados estão de acordo com os observados por difração de raios X.

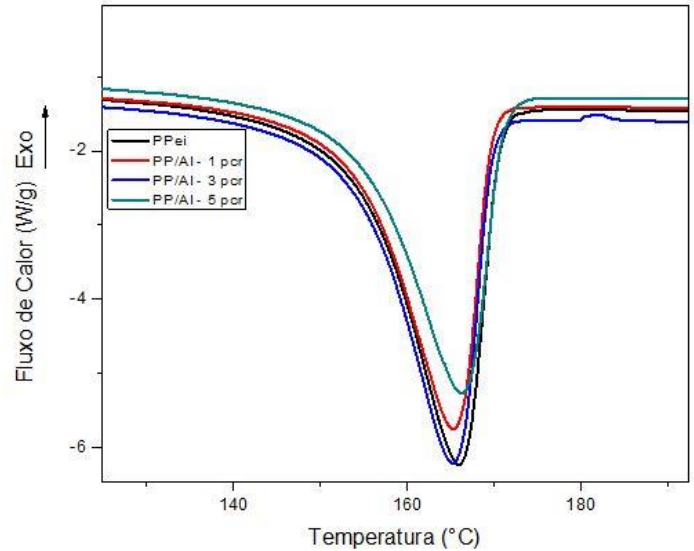

(a)

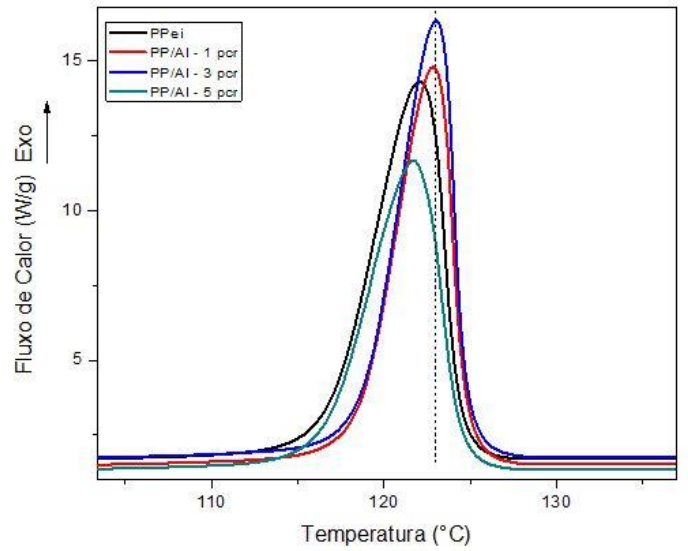

(b)

Figura 4: Termogramas de fusão (a) e cristalização (b) do PP e dos compósitos de PP/alumina.

Tabela 1: Temperaturas de fusão cristalina (Tm), de cristalização (Tc) e grau de cristalinidade (Gc) do PP e dos compósitos de PP/alumina.

\begin{tabular}{l|c|c|c}
\hline COMPOSIÇÃO & $\mathbf{T m}\left({ }^{\circ} \mathbf{C}\right)$ & Tc $\left({ }^{\circ} \mathbf{C}\right)$ & Gc (\%) \\
\hline $\mathrm{PP}$ & 165,9 & 122,0 & 36,7 \\
\hline $\mathrm{PP} / \mathrm{Al}-1 \mathrm{pcr}$ & 165,3 & 122,9 & 33,1 \\
\hline $\mathrm{PP} / \mathrm{Al}-3 \mathrm{pcr}$ & 165,2 & 123,0 & 32,6 \\
\hline $\mathrm{PP} / \mathrm{Al}-5 \mathrm{pcr}$ & 166,2 & 121,7 & 29,7 \\
\hline
\end{tabular}

\subsubsection{Propriedades Mecânicas}

A Tabela 2 apresenta os resultados obtidos do módulo de elasticidade, resistência à tração e resistência ao impacto do PP e dos compósitos de PP com 1, 3 e 5 pcr de alumina, obtidos dos ensaios mecânicos de tração e impacto. Pode-se observar um aumento de até $10 \%$ no módulo dos compósitos, com o aumento da concentração de alumina, isto pode ser explicado pelo fato de que a alumina tem maior rigidez que a matriz de polipropileno, estes resultados estão de acordo com os de MIRJALILI et al. [31]. A resistência à tração dos compósitos teve pouca alteração, reduziu menos de $10 \%$ com 5 pcr de alumina. $\mathrm{O}$ aumento na rigidez pode ser atribuído a incorporação das nanocargas, devido à formação de uma interfase rígida entre a matriz e as partículas. No entanto, outro mecanismo que também pode ser responsável pelo aumento da rigidez em compósitos é a formação de agregados de nanopartículas [11]. Com relação à resistência ao impacto, pode-se verificar que o aumento do teor de alumina nos compósitos, diminui progressivamente a resistência dos mesmos, isto implica que as partículas e/ou aglomerados de alumina, provavelmente atuaram como concentradores de tensão como foi observado nas fotomicrografias das Figuras 5 (b, c, d), a presença da alumina cujas dimensões estão entre 5 e $20 \mu \mathrm{m}$. ZHAO e LI [12] observaram no ensaio de impacto do tipo Izod que a resistência ao impacto de nanocompósitos com nanopartículas de $\mathrm{Al}_{2} \mathrm{O}_{3}$ modificada com o agente silano em matriz de PP, aumentou inicialmente com a adição de $1,5 \%$ em peso de $\mathrm{Al}_{2} \mathrm{O}_{3}$ e diminuiu ligeiramente com a adição de 3,0 e 5,0\%. Os autores atribuíram à redução a formação de aglomerados devido à má dispersão das partículas de alumina na matriz de PP. SILVA [32] verificou um aumento no módulo e uma redução na resistência à tração e ao impacto, similar ao encontrado neste trabalho, e atribuiu tais resultados à presença de aglomerados de alumina na matriz polimérica que foram observados no MEV. 
Tabela 2: Valores de módulo de elasticidade (E), resistência à tração (RT) e resistência ao impacto (RI) do PP e dos compósitos PP/alumina.

\begin{tabular}{l|c|c|c}
\hline COMPOSIÇÃO & $\mathbf{E}(\mathbf{G P a})$ & $\mathbf{R T}(\mathbf{M P a})$ & $\mathbf{R I} \mathbf{( J / m})$ \\
\hline $\mathrm{PP}$ & $1,9 \pm 0,01$ & $35,3 \pm 0,4$ & $24,8 \pm 1,7$ \\
\hline $\mathrm{PP} / \mathrm{Al}-1 \mathrm{pcr}$ & $1,9 \pm 0,01$ & $35,3 \pm 0,2$ & $23,7 \pm 2,1$ \\
\hline $\mathrm{PP} / \mathrm{Al}-3 \mathrm{pcr}$ & $2,0 \pm 0,05$ & $34,0 \pm 0,2$ & $21,2 \pm 0,8$ \\
\hline $\mathrm{PP} / \mathrm{Al}-5 \mathrm{pcr}$ & $2,1 \pm 0,05$ & $33,0 \pm 0,1$ & $19,6 \pm 0,9$ \\
\hline
\end{tabular}

\subsubsection{Análise morfológica}

Na Figura 5 são mostradas as micrografias do PP (Figura 5a) e dos compósitos de PP/Alumina, contendo 1, 3 e 5 pcr de alumina (Figuras 5b-d), todas com o aumento de 1000 X. Nas imagens das Figuras 5 (b) a (d) podem ser observadas as partículas de alumina dispersas na matriz de polipropileno (destacadas pelos círculos brancos). Verifica-se partículas e/ou aglomerados de partículas com grandezas entre 5 e $20 \mu \mathrm{m}$. A identificação destas partículas foi feita utilizando a técnica de EDX na área detalhada do compósito (ver Figura 5d), a análise confirmou por meio da composição química qualitativa que as partículas dispersas são de alumina (ver Figura 5e).
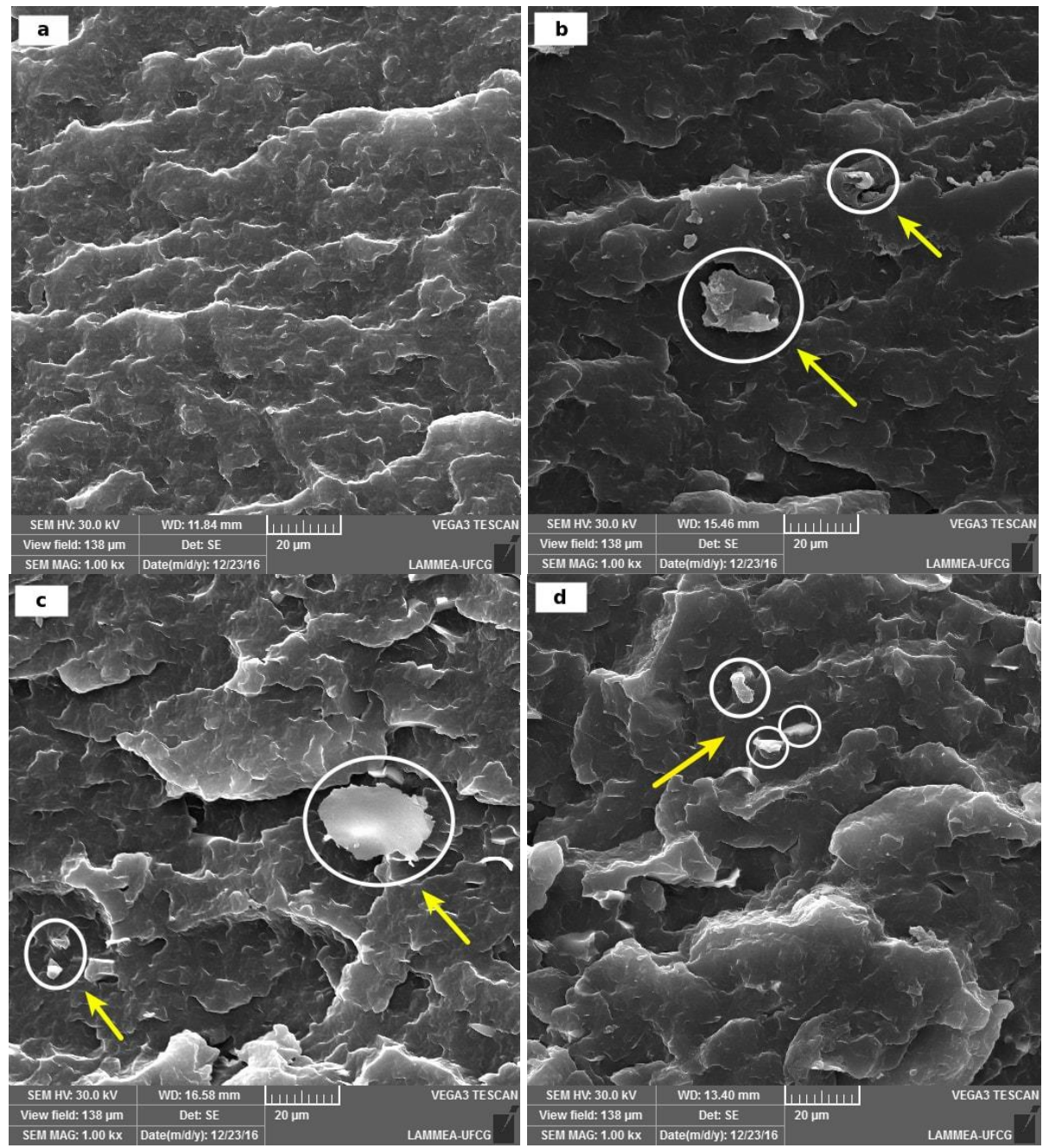


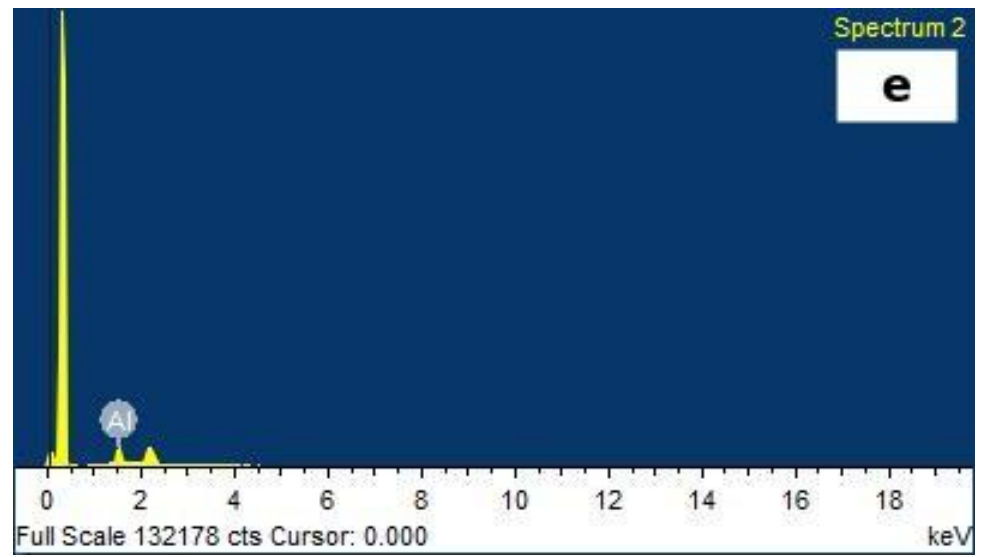

Figura 5: Fotomicrografias obtidas por MEV: (a) PP; (b) PP/Alumina - 1 pcr; (c) PP/Alumina - 3 pcr; (d) PP/Alumina 5 pcr e (e) EDX do compósito PP/Alumina - 5 pcr.

\subsubsection{Teste de Inflamabilidade Horizontal (UL 94 HB)}

A Tabela 3 apresenta os valores e as características apresentadas pelos materiais, obtidos durante a realização do ensaio de inflamabilidade, segundo norma UL 94HB. Observa-se que, ao adicionar alumina no PP, ocorre atraso no processo de queima dos corpos de prova devido à redução dos valores da velocidade, ou seja, os compósitos demoram mais tempo para queimar. Durante o ensaio, também foi possível verificar que o tempo de ignição dos corpos de prova dos compósitos era maior. Provavelmente, o atraso na queima dos compósitos esteja relacionado com a diminuição da difusão das moléculas de oxigênio para o interior da amostra devido à propriedade de barreira das partículas dispersas, o que sugere ter ocorrido com a alumina. Portanto, a alumina em concentrações de até 5 pcr atua como retardante de chama no PP, promovendo um retardo no processo de queima, e durante o ensaio percebia-se que a emissão de fumaça e o gotejamento diminuíam à medida que o teor de alumina aumentava. Outros autores, BARBOSA et al. [33] e RAY e OKAMOTO [34], também verificaram este mesmo efeito quando utilizaram argilas dispersas em matrizes poliméricas a base de poliolefinas.

Tabela 3: Valores da velocidade de queima ( $\mathrm{mm} / \mathrm{min})$ e características da queima do PP e dos compósitos de PP/alumina.

\begin{tabular}{l|c|c|c|c}
\hline COMPOSIÇÃO & $\begin{array}{c}\text { VELOCIDADE DE } \\
\text { QUEIMA (mm/min) }\end{array}$ & CHAMA & FUMAÇA & GOTEJAMENTO \\
\hline $\mathrm{PP}$ & $49,6 \pm 2,1$ & Alaranjada & $\begin{array}{c}\text { Preta com muita } \\
\text { fuligem }\end{array}$ & Gotejou bastante \\
\hline $\mathrm{PP} / \mathrm{Al}-1 \mathrm{pcr}$ & $40,9 \pm 4,1$ & Alaranjada & Preta com fuligem & Gotejou bastante \\
\hline $\mathrm{PP} / \mathrm{Al}-3 \mathrm{pcr}$ & $39,2 \pm 1,5$ & Alaranjada & Preta com fuligem & Gotejou pouco \\
\hline $\mathrm{PP} / \mathrm{Al}-5 \mathrm{pcr}$ & $33,8 \pm 5,6$ & Alaranjada & Preta com fuligem & Gotejou pouco \\
\hline
\end{tabular}

\subsubsection{Propriedades reológicas em regime dinâmico-oscilatório.}

A Figura 6 (a-b) ilustra as propriedades reológicas sob cisalhamento em regime oscilatório do PP e dos compósitos de PP/alumina, com 1, 3 e 5 pcr de alumina. A Figura 6 (a) ilustra a viscosidade complexa $\left(\eta^{*}\right)$ em função da frequência angular $(\omega)$. Observa-se que todos os sistemas apresentam o comportamento pseudoplástico, no qual a viscosidade complexa diminuiu com a frequência e se aproxima do polímero puro em frequências elevadas acima de $100 \mathrm{rad} / \mathrm{s}$. Isto se deve ao fato do alinhamento preferencial das partículas da carga e/ou das moléculas do polímero, no sentido do escoamento (campo de fluxo), oferecer menor resistência a deformação, conforme reportado por KIM et al. [35], CASSAGNAU [36] e LEE et al. [37]. Observa-se ainda que à medida que a concentração de alumina aumentou a viscosidade diminuiu, em geral espera-se o contrário, ou seja, com o aumento da concentração de cargas rígidas em matrizes poliméricas a viscosidade tende a aumentar. Portanto, provavelmente a redução da viscosidade está associada a degradação da matriz polimérica induzida pelos insumos a base de elementos metálicos não reagidos durante a síntese da alumina. $\mathrm{Na}$ 
Figura 6 (b) observa-se que o módulo de armazenamento $\left(\mathrm{G}^{\prime}\right)$ dos compósitos quando comparados ao PP puro em baixas frequências $(<1 \mathrm{rad} / \mathrm{s})$, tem um pequeno aumento com a concentração de alumina e sua inclinação torna-se menor, isto pode ser atribuído a formação de um pseudo-sólido, ou seja, quanto maior o teor de alumina, aumenta as possibilidades de contato entre as partículas e/ou aglomerados de partículas dispersos na matriz polimérica enrijecendo o sistema, corroborando o resultado obtido no módulo elástico no ensaio mecânico de tração.

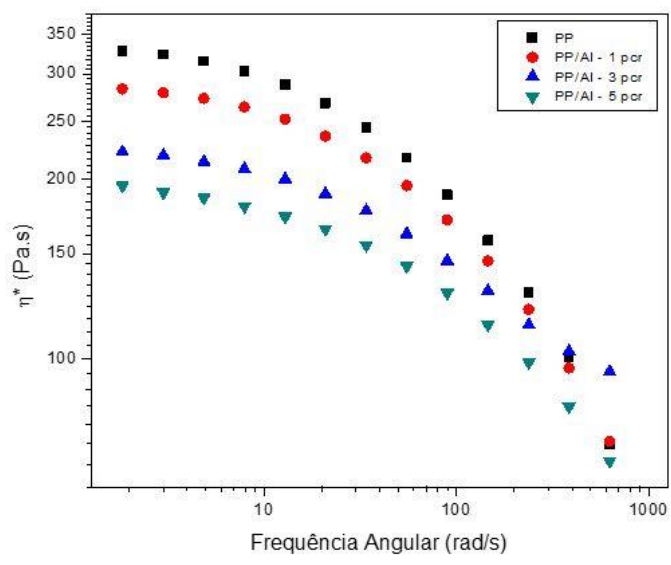

(a)

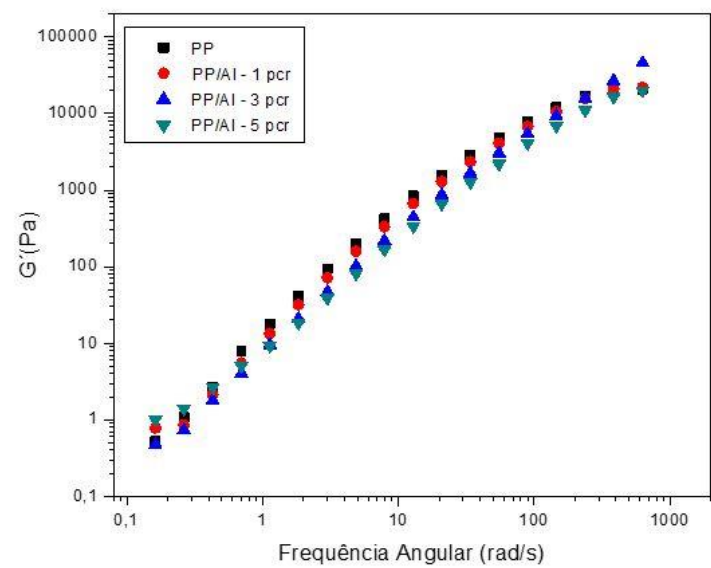

(b)

Figura 6: (a) Viscosidade complexa e (b) Módulo de armazenamento em função da frequencia para o PP e para os compósitos PP/alumina.

\section{CONCLUSÕES}

Neste trabalho, investigou-se o efeito da alumina sintetizada em laboratório por reação de combustão nas propriedades de compósitos de PP/Alumina e pôde-se concluir que a alumina sintetizada que possui estrutura cristalina do tipo coríndon não alterou a estrutura cristalina do PP e nem houveram mudanças significativas das transições térmicas e das propriedades mecânicas quando adicionou-se alumina ao PP. Porém, a alumina atuou como retardante de chama e modificou as propriedades reológicas onde, a viscosidade diminuiu a medida que aumentou o teor de alumina enquanto que o módulo de armazenamento aumentou proporcional ao aumento do teor de alumina, confirmando o enrijecimento dos compósitos, conforme observado nas propriedades mecânicas.

\section{AGRADECIMENTOS}

Os autores agradecem a CAPES e ao CNPq pelo apoio financeiro.

\section{BIBLIOGRAFIA}

[1] ORELlANA, F., LISPERGUER, J., NUÑEZ, C., "Synthesis and characterization of polypropylenesilica, alumina and titania nanoparticles, prepared by melting", Journal of the Chilean Chemical Society, v. 59, n. 1, pp. 2389-2393, Mar. 2014.

[2] RODRIGUES, A.W., Organofilização de argilas bentoníticas e aplicação no desenvolvimento de nanocompósitos com matriz de polipropileno, Tese de D.Sc., PRODEP/UFCG, Campina Grande, PB, Brasil, 2009.

[3] BhattacharyA, S.N., KAMAL, M.R., GUPTA, R.K., Polymeric Nanocomposites: Therory and Practice, 1 ed., Munich, Carl Hanser Verlag, 2008.

[4] RAO, V.S., YADAV, V., KUMAR, V.K., et al., "Combined effect of nanoclay and alumina addition on structure, TGA, DMA characteristics of nanoclay, and alumina-filled polypropylene nanocomposites", Journal of Thermoplastic Composite Materials, v. 25, n. 7, pp. 851-863, Aug. 2011. 
[5] SILVA, G.D.A., ALVES, K.G.B., ALMEIDA, Y.B., et al., "Effect of Alumina Ceramic Powder Dispersion on Mechanical Properties of polypropylene polymers", Materials Science Forum, v. 727-728, pp. 1729-1733, Aug. 2012.

[6] GARCÉS, J.M., MOLL, D.J., BICERANO, J., et al., "Polymeric nanocomposites for automotive applications", Advanced Materials, v. 12, n. 23, pp. 1835-1839, Dec. 2000.

[7] SUN, D., ZHANG, R., LIU, Z., et al., "Polypropylene/silica nanocomposites prepared by in-situ sol-gel reaction with the aid of $\mathrm{CO}_{2}$ ", Macromolecules, v. 38, n. 13, pp. 5617-5624, May. 2005.

[8] ELLIS, T.S., D“ANGELO, J.S., "Thermal and mechanical properties of a polypropylene nanocomposite”, Journal of Applied Polymer Science, v. 90, n. 6, pp. 1639-1647, Feb. 2003.

[9] TRUONG, L.T., LARSEN, A., HOLME, B., et al., "Morphology of syndiotactic polypropylene/alumina nanocomposites", Polymer, v. 52, n. 4, pp. 1116-1123, Jan. 2011.

[10] TEE, D.I., MARIATTI, M., AZIZAN, A., et al., "Effect of silane-based coupling agent on the properties of silver nanoparticles filled epoxy composites", Composites Science and Technology, v. 67, n. 11-12, pp. 2584-2591, Jan. 2007.

[11] PEDRAZZOLI, D., KHUMALO, V.M., KARGER-KOCSIS, J., et al., "Thermal, viscoelastic and mechanical behavior of polypropylene with synthetic boehmite alumina nanoparticles", Polymer Testing, v. 35, pp. 92-100, Mar. 2014.

[12] ZHAO, H., LI, R.K.Y., "Crystallization, mechanical, and fracture behaviors of spherical alumina-filled polypropylene nanocomposites", Journal of Polymer Science Part B: Polymer Physics, v. 43, n. 24, pp. 3652-3664, Nov. 2005.

[13] DUAN, Y., FU, Z., "Influence of poly(n-octadecyl acrylate) on mechanical properties, melting behavior, and morphology of polypropylene/aluminum trihydroxide composites", Fire and Materials, v. 36, n. 8, pp. 614-622, Set. 2011.

[14] LI, B., LI, R., XIE, Y., "Properties and effect of preparation method of thermally conductive polypropylene/aluminum oxide composite", Journal of Materials Science, v. 52, n. 5, pp. 2524-2533, Nov. 2016.

[15] LEAL, E., NEIVA, L.S., GAMA, L., et al., "Síntese do catalisador NiAl2O4 por reação de combustão", Revista Eletrônica de Materiais e Processos, v. 3.3, pp. 47-55, Dec. 2008.

[16] CORDEIRO V.V., FREITAS, N.L., VIANA, K.M.S, et al., "Influence of the external heating type in the morphological and structural characteristics of alumina powder prepared by combustion reaction", Materials Science Forum, v. 660-661, pp. 58-62, 2010.

[17] SILVA, M.C., COSTA, N.C O., LIRA, D.S., et al., "High energy milling of alumina synthesized by combustion reaction using a vertical shaft attritor mill: influence of the milling time length", Materials Science Forum, v. 820, pp. 155-160, Jun. 2015

[18] COSTA, A.C.F.M.; KIMINAMI, R.H.G.A., "Dispositivo para a produção de manocompósitos cerâmicos em larga escala por reação de combustão e processo contínuo de produção de nanocompósitos", Brasil, Depósito de Patente. Depositada em 25/01/2012. Revista de Propriedade Industrial - RPI, BR 102012 002181-3, 2012. - Não tem modelo para patente.

[19] AMERICAN SOCIETY FOR TESTING AND MATERIALS. ASTMD D 638 - 14: standard test method for tensile properties of plastics. West Conshohocken, 2014.

[20] AMERICAN SOCIETY FOR TESTING AND MATERIALS. ASTMD D 256 - 10: standard test methods for determining the izod pendulum impact resistance of plastics. West Conshohocken, 2010.

[21] AGRAWAL, P., ALVES, A.M., BRITO, G.F., CAVALCANTI, S.N., ARAÚJO, A.P.M, MÉLO, T.J.A., "Effect of Ethylene-Methyl Acrylate Compatibilizer on the Thermo-Mechanical, Rheological, and Morphological Properties of Poly(Lactic Acid)/Biopolyethylene/Clay Biocomposites", Polymer Composites, pp. 110, 2016.

[22] Standard for testing for flammability of plastic materials for parts in devices and appliances. Northbrook, 2013.

[23] FREITAS, N.L., FAGURY NETO, E., LIRA, H.L., et al., "Combustion synthesis of alfa- $\mathrm{Al}_{2} \mathrm{O}_{3}$ powders", Materials Science Forum, v. 530-31, pp. 631-636, Nov. 2006.

[24] CASTRO, R.H.R., GOUVÊA. D., "Efeito do íon Mn como aditivo na transição de fase $\gamma \rightarrow \alpha$ da alumina", Cerâmica, v. 49, n. 309, pp. 55-60, 2003. 
[25] SILVA, M.C., CUNHA, R.B.L., KIMINAMI, R.H.G.A., et al., "Estudo da estrutura e morfologia da alumina preparada por reação de combustão usando recipientes de diferentes capacidades de produção", In: $56^{\circ}$ Congresso Brasileiro de Cerâmica, pp. 628-638, Curitiba, Jun. 2012.

[26] SHARMA, A., MODI, O.P., GUPTA, G.K., "Combustion synthesis of nanocrystalline $\mathrm{Al}_{2} \mathrm{O}_{3}$ powder using aluminium nitrate and urea as reactants - influence of reactant composition", Advances in Applied Science Research, v. 3, n. 6, pp. 3819-3824, 2012.

[27] FERET, F.R., ROY, D., BOULANGER, C., "Determination of alpha and beta alumina in ceramic alumina by X-ray diffraction”, Spectrochimica Acta Part B: Atomic Spectroscopy, v. 55, n. 7, pp. 1051-1061, Jul. 2000.

[28] RAMALHO, M.A.F., FREITAS, N.L., COSTA, A.C.F.M., et al., "Morphological and structural analys os alfa-A12O3 modified with Zr prepared by combustion reaction”, Materials Science Forum, v. 591-593, p. 750-754, Aug. 2008.

[29] LIBANO, E., VISCONTE, L.L., PACHECO, É.B., "Propriedades térmicas de compósitos de polipropileno e bentonita organofílica", Polímeros, v. 22, n. 5, pp. 430-435, Oct. 2012.

[30] CANEVAROLO JÚNIOR, S.V., Ciência dos polímeros, 2 ed., São Paulo, Artliber, 2002.

[31] MIRJALILI, F., CHUAH, L., SALAHI, E., "Mechanical and morphological properties of polypropylene/nano alpha-A12O3 composites”, The Scientific World Journal, v. 2014, pp. 1-12, Feb. 2014.

[32] SILVA, V.L.D., "Comportamento mecânico e de flamabilidade de compósitos de polipropileno reciclado com fibra de coco e hidróxido de alumínio”, M.Sc., PPEM/UFPA, Belém, PA, Brasil.

[33] BARBOSA, R., ARAÚJO, E.M., MÉLO, T.J.A., et al., "Preparação de argilas organofílicas e desenvolvimento de nanocompósitos de polietileno. Parte II: comportamento de inflamabilidade", Polímeros: Ciência e Tecnologia, v. 17, n. 2, pp. 104-112, Jun. 2007.

[34] RAY, S.S., OKAMOTO M., "Polymer/layered silicate nanocomposites: a review from preparation to processing”, Progress in Polymer Science, v. 28, n. 11, pp. 1539-1641, Nov. 2003.

[35] KIM, D.H., FASULO, P.D., RODGERS, W.R., et al., "Structure and properties of polypropylene-based nanocomposites: effect of PP-g-MA to organoclay ratio", Polymer, v. 48, n. 18, pp. 5308-5323, Jul. 2007.

[36] CASSAGNAU, P., "Melt rheology of organoclay and fumed sílica nanocomposites”, Polymer, v. 49, n. 9, pp. 2183-2196, Apr. 2008.

[37] LEE, J., YANG,S-B., JUNG, H-T. "Carbon Nanotubes-Polypropylene Nanocomposites for Electrostatic”, Macromolecules, v. 42, n. 21, pp. 8328-8334, Oct. 2009. 